\title{
Factors Affecting Savings And internal lending communities in Informal Finance Groups on Pastoral Communities in Kenya, A Case of West Pokot County
}

\author{
MBA Student: Jacob Nalanda Nasong'o \\ Supervisor: Dr. Anthony Osoro
}

Purpose: This study has explored the factors affecting savings and internal lending communities (SILC). The specific objectives were: financial viability, financial sustainability, financial acceptability and Information and Communication Technology. The literature review is in line with the variables under this study, the target population established was 440 covering Women groups, Youth groups, elder's council, youth association, livestock trader's cooperative society, Financial institutions and Government agencies in Kapenguria Division.

Keywords: financial viability, financial sustainability, Information and Communication Technology and financial acceptability

DOI: $10.7176 /$ RJFA/10-9-03

Publication date:May $31^{\text {st }} 2019$

\subsection{Introduction}

The history of Community Micro-Finance Schemes is ancient, dating back at least to 16th C, when Yoruba slaves carried out Merry-Go-Round activities to the Caribbean, as part of their institutional baggage - social capital (Donahue, 1999). Savings and Internal Lending Communities (SILCs) are a type of community-based Accumulating Savings and Credit Association (ASCA). SILCs build on an ASCA model developed by CARE in Niger (the "Mata Masu Dubara" or "Women on the Move" Project, often referred to as MMD), ASCAs themselves are improvements on traditional merry-go-rounds, or ROSCAs, that are prevalent in many communities around the world. While traditional ROSCAs provide their members with an extremely simple and transparent way to build useful lump sums, and as a result can form and spread without external assistance, they have their limitations (Copestake, Johnson \& Wright, 2002).

Savings have been defined as the excess of income over consumption (Donahue, 1999). In the real sense, it is that part of after-tax income that is not spent; hence households have just two choices about what to do with their income after taxes -use it to consume or save it. Savings serve as invaluable reserves, as insurance against crisis factors such as illness, natural disaster, theft and other necessary human needs such as health, food, education and housing which can easily drive the poor into destitutions (Catholic Relief Services (CRS),2010). Like credit, saving helps households turn a sequence of small sums into useful lump sums. Households prefer to save rather than borrow because it has a low cost and gives them more control over their lives. Donahue (1999), observed that savings is a safer approach and one that is appropriate for all families

12as at times borrowing is a high risk decision for poor families especially those living in informal settlement areas (Anderson. \& Baland, 2002). Poor people have multiple demands on their scant resources. As such, they normally save for specific time and purposes mainly in situations that motivate them to save more. Field surveys reveal that poor people prefer small regular contributions that are collected at their convenient time and placeto motivate saving discipline. At other time as it was observed, some features like "illiquidity or commitment savings" that hinder withdrawal also facilitate more savings (Donahue, 1999).Thomas (1995) asserted that in urban informal settlements, it is very difficult to protect savings from theft, inflation or the demands of everyday life. It is even more difficult to obtain credit or loan (Adinyira, Oteng-Seifah \& AdjeiKumi,2007). Faced with institution policies and services that are frequently hostile, inadequate or indifferent to their concerns, the urban poor have little choice but to valiantly deploy a range of coping strategies, chief among them being the use of their social networks to provide everything from credit, savings and physical security to information about housing, financing and employment opportunities (Creevey, \& DAI, 2008).Informal financial markets heterogeneous, incorporating all financial transactions consummated outside the functional scope of formal financial regulations (Beijuka\& Odele (2007).Informal financial participants include money lenders, Rotating Savings and Credit Associations(ROSCAs),mobile saving collectors, mutual assistance groups, landlords, neighbors, friends and family members (Creevey \& DAI, 2008).Most informal finance groups in slums specialize 13in either lending or savings and they tend to be membership based. According to Ashley and Hussein (2008), most informal finance groups have been developed in response to the demand of a distinct clientele and each unit tends to serve a particular market niche.

Despite advances made by microfinance institutions in giving the poor access to credit, studies have estimated that 2.7 billion adults in the developing world remain unbanked (CGAP, 2009).In 2003, the World Bank reported that people living in slums are usually financially excluded and therefore rely on informal 
financial tools for their finances (WB, 2003). The report also established that most of the households in Latin America and the Caribbean have no access to formal financial institutions. In a later report (2010), World Bank reported that 2.9 billion adults or half the world adult population is unbanked, and 2.7 billion of them or $90 \%$ are from low income and middle income countries.

\subsection{Statement of the Problem}

Promoting efficient, sustainable and widely accessible rural financial systems remains a major development challenge in Kenya (Kono \&Takahashi (2010), With about $73 \%$ of the pokots population living in the rural areas and experiencing a high incidence of rural poverty, improved rural finance is crucial in achieving pro-poor growth and poverty reduction goals (Murphy, 2002). However, in most cases development of rural financial systems is hampered by the high cost of delivering the services to small, widely dispersed customers; as well as a difficult financial terrain - characterized by high covariant risks, missing markets for risk management instruments and lack of suitable collateral for credit access. Due to the remoteness and contextual hardships of Kapenguria such as lack of good infrastructure and harsh ecological conditions, penetration of formal financial services has been limited over years. Most pastoral communities tend to have a negative attitude towards monetary savings and focus on accumulating wealth in form of livestock.

Pokot community is no exception. This situation could be an indicator that significant gaps exist in finance and Investment pipeline among the pastoral Pokot community. Most likely, the lack of organized financial intermediation services together with a relatively rigid culture has slowed socio-economic development of the pokot. Although local development structures such as the Pastoral Community Development Associations (PCDAs) exist in Kapenguria, they tend to lack an organized system of financial intermediation that has ability to spur the desired socio-economic development in the locality (ILIDP SP 2012-2016). This reality presents the Pokot with an opportunity to select the "best-fit" financial services from a pool of prospective service providers from both formal sector (banks, cooperative societies, micro-finance institutions, etc) and informal sector (money lenders, "chama, pyramid schemes and accumulated savings and loan schemes - SILC). Pokots in Kapenguria reside in remote-rural locality hence a financial service is likely to be chosen or adopted if it addresses their unique situation. The researcher is not aware of any scientific investigations undertaken on the study topic. It is hoped that information generated through this study will help reduce existing knowledge gap on influence of SILC model in Informal Finance groups' selection of rural financial services on pastoral communities in Kenya by drawing experiences and lessons learnt in Kapenguria Division.

\subsubsection{Objective of the Study:}

The general objective of this study was to establish the factors affecting savings and internal lending communities on the Pastoral community in Kenya.

The specific objectives of this study were:

1. To examine how financial viability affects savings and internal lending on the Pastoral community in Kenya

2. To assess the effect of financial acceptability affects savings and internal lending on the Pastoral community in Kenya

3. To establish the extent to which Information and Communication Technology affects savings and internal lending on the Pastoral community in Kenya

4. To determine how financial sustainability affects savings and internal lending on the Pastoral community in Kenya

\subsection{Theoretical Framework}

The study was supported by different theories that give an in-depth explanation of influence of SILC in informal finance groups, (financial viability, social-cultural acceptability, information and communication technology and environmental sustainability. The theories rest on the fact that informal finance groups are increasingly being adopted in pastoral communities and rural areas, ( Rajan and Ramcharan, 2011, )

\subsubsection{Banking Theories and Macroeconomics}

The banking and macroeconomics theory was considered to be relevant on understanding how financial friction can determine the inefficiency supply of credit to pastoral communities in Kenya hence provides the theoretical background for this study. Woodford (2010) emphasizes the role of financial frictions in determining an inefficient supply of credit. In a world without financial frictions, savers lend to intermediaries at the same interest rate as that at which intermediaries lend to final borrowers. In the real world, however, the external finance premium is positive (and fluctuating), mainly due to intermediaries' limited ability to leverage their positions. Constraints on the intermediaries' equity accelerate the business cycle: intermediaries react to positive (negative) changes in net worth by intensifying (lessening) their 'supply of intermediation' (Woodford, 2010, p. 32). Financial markets are characterized by the existence of frictions and imperfections. Bernanke et al. (1999) and Eggertsson and Krugman (2012) concentrate on the analysis of the effects of changes in the borrowers' net 
worth; Woodford looks at the fluctuations of the lenders' net worth. In all cases, however, financial intermediation, if considered at all, is dealt with in very general terms, without providing any distinction between different intermediaries and, in particular, without paying much attention to commercial banks

\subsubsection{The Cultural Theory}

The cultural theory is relevant on understanding how culture of pastoral communities can influence savings and internal lending community in Kenya hence providing the theoretical background for this study. Cultural theories examine people within a culture and try to understand or predict how or why they react a certain way towards credit, loan repayment. There are three main models of cultural studies research: production -based studies; textbased cultural studies; and studies of lived cultures. It may be more transformative to rethink each moment in light of the others; importing objects and methods usually developed in relation to one moment into the next "Thompson et al. (1990) claim that their cultural theory is universal. They argue that distinctive sets of values, beliefs and habits (in nations, neighborhoods, tribes and races) are reducible to only a few cultural biases and preferences". Cultural theory is one of many approaches that have been used to cope with the subjectivity inherent in analyzing long term global change. The original aim of Cultural Theory was to create a typology of social forms that aligned with, Classificatory schemes developed by the upper-class social theorists like Emile Durkheim, Karl Marx, Max Weber and so on, and the new evidence collected in ethnographic studies (Verweij et al., 2006). Rather than trying to be complete, we want to provide the insight about the evolvement of Cultural Theory. Large part of this report is derived from a comparison made by Thompson et al. (1990 part two) in which they try to show that despite the unconventional language of "grid" and "group", their typology refers to many of the same types of social relations.

\subsubsection{Innovation Diffusion Theory}

The Innovation Diffusion theory is considered to be relevant on understanding how technology can influence pastoral communities in Kenya on savings and lending hence provides the theoretical background for this study. The innovation diffusion theory (IDT) has remained one of the strong theories to predict the diffusion of innovations in a social system. Smartphone is one such product that falls in the category of innovation that changes with passage of time. Smartphones are becoming smarter by each day. The addition of new features in a way reinvents the use of this product. Instead of focusing on persuading individuals to change, it sees change as being primarily about the evolution or "reinvention" of products and behaviors so they become better fits for the needs of individuals and groups.

In diffusion of innovations, it is not people who change, but the innovations themselves (Les Robinson, 2009). The Innovation Diffusion Theory integrates other formal financial services with the informal financial services Compatibility: this is the extent to which adopting the innovation is compatible with what people do (Kaasinen, 2005). It is the degree to which an innovation is perceived as consistent with consumer needs, values and beliefs, previous ideas and past experiences. It helps give meaning to the new idea and regard it as more familiar (Francesco, 2012). The more compatible the innovation the better chances of adoption. E.g. a firm which wants to introduce a new line of operations will find it suitable to have a technology that doesn't a much impact on the existing lines of operation. If the new line will disrupt the existing operational lines it may increase the cost involvement and the firm may scrap the deal. However one shall not blank out this possibility that two much compatibility can be sometimes a problem as the users may find it unworthy to try a new innovation or might not perceive it to be an innovation.

\subsubsection{Growth Theory}

The growth theory is considered to be relevant on understanding how environment can influence pastoral communities in Kenya on savings and lending hence provides the theoretical background for this study. Tackling global and local environmental issues simultaneously will require a global multi-stakeholder partnership (HLP, 2013), as well as partnerships at multiple levels of governance - from community and national levels up to international levels. A twin-track policy agenda of national and international action can help to achieve environmental sustainability in all countries, In July 2013, drawing on the work of the OECD2 and other international organizations, 3 the G20's Development Working Group (DWG) hosted a dialogue with representatives from low-income developing countries on the lessons learned from their own experiences in designing and implementing inclusive green growth strategies and policies. Water, food and energy are closely interlinked. For example, options to increase water security - such as long-haul transfer and desalination - are often energy-intensive. At the same time, water is critical for meeting future energy demands without damaging the climate. The energy sector already accounts for an estimated $15 \%$ of the world's freshwater withdrawals, and this is projected to increase by $20 \%$ between 2010 and 2035 (IEA, 2012).

Water use for energy can reduce the availability of water and can also be polluting and damage freshwater ecosystems. Policies promoting biofuels as an alternative to fossil fuels have led to increased raw commodity prices and to pressure on land for growing food; in some cases this is affecting food prices for poor consumers in developing countries and undermining food security (King, 2013). OECD work on agricultural investment confirms that global agriculture is increasingly linked to energy markets (OECD and FAO, 2012). Higher oil 
prices are a fundamental factor behind high agricultural commodity price projections, as they increase oil-related costs of production, as well as demand for biofuels and agricultural feedstock. By 2021, global production of bioethanol and biodiesel is projected to almost double, with biofuels consuming a significant share of the global production of sugarcane (34\%), vegetable oil (16\%), and coarse grains (14\%).

\subsection{Conceptual Framework}

This section presents the Conceptual Framework which shows the link between the study concepts and the three areas identified for investigation in the study. Figure 2.1 shows the relationship between variables identified in the problem statement and objectives.

Independent Variables

Dependent Variable

\section{Financial Viability \\ - Other financial services, \\ - startup funds, credit \\ - period, Loan repayment system,}

\section{Financial Acceptability}

- Social capital, social

- funds, social status, motivation,

- cultural and religion issues and trust building/breakingb

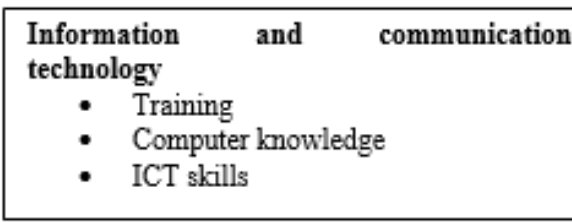

\section{Financial Sustainability}

- Social capital development,

- provision of social funds

- contribution to social status,

- group motivation, cultural and religious issues and trust building/breaking

\begin{tabular}{|l} 
Savings and Internal \\
Lending to Pastoral \\
Communities \\
- Improve livelihood \\
of the community \\
- Continual \\
upgrading of \\
informal finance \\
system \\
Improved lending \\
services to the \\
household \\
Promotes culture \\
of savings
\end{tabular}

Figure 2.1 Conceptual Framework

\subsection{Financial Viability}

Skolas Vards (2014) defines financial viability as the ability to generate sufficient income to meet operating payments, debt commitments and, where applicable, to allow growth while maintaining service levels. Ardener and Burman (1995), define informal finance as contracts or agreements conducted without reference or recourse to the legal system to exchange cash in the present, for promises of cash in the future. SILCs are self-help organizations which mobilize their own resources mainly from members weekly savings, borrow to finance their MSEs, repay their loans and share growth using profits arising from credit to members and fines. While both informal finance and microfinance serve poor, unbanked people, informal finance derives from the grassroots, bottom-up demand of the poor for appropriate financial services, whereas microfinance derives from donordriven, top-down supply. The common wisdom is that informal finance is a mine of lessons to inform the design of microfinance as elaborated by Ardener and Burman, 1995; Bouman 1995: Burkett. 1988; Caskey, 1994; Christen 1989; Graham 1992; Von Pischke 1992.

\subsubsection{Financial acceptability}

Despite the seemingly recent appeal of cultural concepts in financial research, it is gaining a large audience. The studies by Stulz and Williamson (2003) and by Grinblatt and Keloharju (2001), relating culture to investors' protection, and to stockholding, respectively, are now largely acknowledged by the financial community. Citing classical works by Greif, Lal, Landes, North, and even Max Weber - Stulz and Williamson (2003: 314, references therein) ${ }^{* * *}$ emphasize their general belief that culture is highly important for the effective study of financial phenomena. Ramirez and Tadesse (2007: 8) note the growing importance of references to "national culture indices", and Hofstede, in the financial and economic literatures. Some authors go even further. De Jong 
and Semenov (2002: 2) suggest that a specific "cultural view" should be developed, in part to compete with the law and finance approach, which has blossomed since La Porta, et al. (1997, 1998). Breuer and Quinten (2009)* suggest the establishment of "Cultural Finance" as an autonomous discipline. Simultaneously, "cultural biases" have been posited by academics of Behavioral Finance as early as 1999 (Shiller, 1999: 1), and those ideas are currently being more closely considered (Statman, 2007, 2008). Yet, in finance, neither any review, nor any consistent cultural framework, has been proposed to date.

\subsubsection{Information and Communication Technology}

Christensson, P. (2010, January 4) defines ICT as Information and Communication Technologies." ICT refers to technologies that provide access to information through telecommunications. It is similar to Information Technology (IT), but focuses primarily on communication technologies. This includes the Internet, wireless networks, cell phones, and other communication mediums. Which is very essential for pastoral community members in upgrading the system if saving and internal lending community.

In the past few decades, information and communication technologies have provided society with a vast array of new communication capabilities. For example, people can communicate in real-time with others in different countries using technologies such as instant messaging, voice over IP (VoIP), and video-conferencing. Social networking websites like Facebook allow users from all over the world to remain in contact and communicate on a regular basis. Modern information and communication technologies have created a "global village," in which people can communicate with others across the world as if they were living next door. For this reason, ICT is often studied in the context of how modern communication technologies affect society.

\subsubsection{Financial Sustainability}

Financial sustainability is defined as responsible interaction with the financial to avoid depletion or degradation of natural resources and allow for long-term environmental quality. The practice of environmental sustainability helps to ensure that the needs of today's population are met without jeopardizing the ability of future generations to meet their needs. When we look at the natural environment, we see that it has a rather remarkable ability to rejuvenate itself and sustain its viability. For example, when a tree falls, it decomposes, adding nutrients to the soil. These nutrients help sustain suitable conditions so future saplings can grow. When nature is left alone, it has a tremendous ability to care for itself. However, when man enters the picture and uses many of the natural resources provided by the environment, things change. Human actions can deplete natural resources, and without the application of environmental sustainability methods, long-term viability can be compromised J.Morelli (2011)

\subsubsection{Savings and Internal Lending to Pastoral Communities}

Ardener and Burman (1995), define informal finance as contracts or agreements conducted without reference or recourse to the legal system to exchange cash in the present, for promises of cash in the future. SILCs are selfhelp organizations which mobilize their own resources mainly from members weekly savings, borrow to finance their MSEs, repay their loans and share growth using profits arising from credit to members and fines. While both informal finance and microfinance serve poor, unbanked people, informal finance derives from the grassroots, bottom-up demand of the poor for appropriate financial services, whereas microfinance derives from donor-driven, top-down supply. The common wisdom is that informal finance is a mine of lessons to inform the design of microfinance as elaborated by Ardener and Burman, 1995; Bouman 1995: Burkett. 1988; Caskey, 1994; Christen 1989; Graham 1992; Von Pischke 1992. Yoder, 1993 found out that MFIs in Kenya use diverse methods of microfinance molded from the Gramean Bank model. This model administers credit and savings. MFI's organize clients into groups for purpose of attaining economies of scale from the small scale transactions and instituting small group guarantee mechanism, credit appraisal is based on character assessment and trust of the group rather than viability of projects to be financed and collateral and the focus is on financing very small business and the poor ( Khandker et al, 1995). Thus one can be denied credit if he/she does not belong to a group even if has ability to repay.

Study by Oketch (1993) on the demand and supply of MSE's finance in Kenya identified four methodologies mainly individuals credit, individual credit with technical assistance, group credit and group credit with technical assistance. The last two in my view are based on SILC concept hence major source of financing MSE's has roots in SILC spirit. According to Dondo (1994) organizations give credit in two ways, individuals or through groups. Dondo. Oketch. Yoder and Rukwaro studies are consistent on approaches used in Kenya to finance MSEs. Though the Kenyan situation is consistent. Gurgand (1994) did not identify any one single model for successful rural financial intermediation, rather a variety of operating models to improve savings mobility, provide credit and increase flexibility in service delivery were being used.

\subsection{Research Methodology}

\section{Research Design}

A research design is a plan and strategy of investigating a phenomenon and it seeks to obtain answers to various study questions (Kerlinger, 1973). The study adopted a sample survey design to help undertake descriptive 
research. Kothari (2004) defines a sample survey as a way of collecting data from a population with a view towards making statistical inferences about the population using the sample. The descriptive survey design was considered suitable for the study since it would help obtain data that describes characteristics of the study topic. Descriptive statistics discover and measure cause and effect relationships among variables (Cooper et al, 2003). It is expected that findings and conclusions made from the case study of Kapenguria, Pokot community will help generate facts and useful information on influence of SILC in Informal finance groups amongst the pastoralist communities in Kenya.

\subsection{Target Population}

Population is a group of knowledgeable people also known as universe (Hair et al., 2007). Cooper and Schindler (2003) define a population as the total collection of elements about which we wish to make inferences. In defining the most appropriate target population, a number of factors unique to Kapenguria division were considered. First, preliminary consultations with the political leadership of the Kapenguria Constituency revealed that it is the practice of the Pokot community to identify, plan and participate in local development projects under the pastoral community development associations (PCDAs). This approach to local development had proven to promote participation and inclusion of all the administrative locations in the Division. Second, it is the norm of the pokot people to speak to visitors (or strangers) through their institutions of local governance. Guided by these two factors and research objectives, it was deemed prudent to define the target population as the total number of PCDAs/ community-based groups/associations, councils, government agencies, faith-based and nongovernmental organizations operating in Kapenguria Division. The target population established to be 68 community-based institutions comprising of: 6 PCDAs covering 6 locations in the Division; 5 NGOs including ILIDP; 28 women groups; 18 youth groups; 1 women council; 1elders council; 1 livestock trader's cooperative society; 1 youth association/network; 5 commercial banks and micro-finance institutions operating in West Pokot County; and 2 Government Agencies (Kapenguria CDF and Provincial Administration representative).

\subsection{Sampling Frame}

A sample is a set of information or data selected from a target population using predefined procedures (Field, 2005). Sampling is the process of selecting a number of individuals for a study in such a way that the individuals selected represent the large group from which they were selected (Mugenda \& Mugenda, 1999). The study selected sample of $10 \%$ of (440) from the targeted population. The goal of stratified random sampling is to achieve desired representation from various subgroups in the population. This method was useful in this study because it is cheap, time-efficient, convenient, and accurate. In descriptive studies ten percent of the accessible population is enough sample size.

\subsection{Sample and Sampling Techniques}

Mugenda and Mugenda (1999) define a sample as a subject of a particular population

This study will use stratified random sampling techniques to select the respondents. Stratified random sampling techniques will be used to pick representative from each stratum; subjects will be selected in such a way that the existing subgroups in the population are more or less reproduced in the sample (Mugenda \& Mugenda, 2003). The method produces accurate representations and there was no concern that any group was left out.

\subsection{Research Instruments}

Data collection was done through questionnaires. A questionnaire is a research instrument comprising a set of questions as well as prompts to gather data from respondents (Roger, 2008). Usually, questionnaires contain a series of questions to be answered in a certain format. They are advantageous to other methods of the survey because they are cheap and require little human effort in the process of administration (Krosnick, 2003). A both open-ended and closed-ended question was used during data collection. That was exploratory in nature to help respondents provide answers without forcing them to select from predetermined choices (Roger, 2008). Openended questionnaires were useful in collecting qualitative data. Closed-ended questionnaires, however, are limited to a set of explicit options where respondents select from (Krosnick, 2003). The explicit options were in the form of multiple choices, rankings, and classifications. Each question was not expected to provide unanticipated or unique answers, but rather, respondents were limited to a series of pre-selected options (Roger, 2008). The questionnaires were availed to the entire sample population both formally and informally. The Likert Scale of 1-3 was used in the closed-end questionnaires where the respondents were expected to choose among the following choices: , agree, unsure and disagree (Norman, 2010). It was also arranged in a logical manner such that the respondents had a clear understanding of the research from the general questions, independent variables, and dependent variable (Norman, 2010). The rating is "unipolar" in the sense that it compares one objective at a time rather than combining all the three sections.

\subsection{Data Collection Procedures}


Data refers to all the information a researcher gathers for study Kothari (2011). There are two types of data; primary and secondary data. According to Maryan (2012), the primary data are those collected for the first time and thus happens to be original in character. The secondary data are those documented by other scholarly writings after validating (Nandama, 2010). Secondary data would therefore refer to information from research articles, books casual interviews as well journals. Collection of primary data was done mainly using semistructured questionnaires. The researcher was concerned with the opinion, perceptions views, feelings and attitudes. Bell (1993) observes that such information is best collected through the use of interviews and questionnaires. A questionnaire was preferred because it was economical to administer and suited all levels of literacy in the sampled population. The secondary data was obtained from published sources (articles in journals), accessible government and micro-finance registries (sources), seminar and workshop power-point presentations accessible online, and programme records on situational analysis

\subsection{Pilot Study}

A pilot study (also referred to as pilot experiment or pilot project) is a small scale reconnaissance carried out to evaluate the feasibility, cost, time, and statistical variability of a sample size (Holborn, 2000). It aims at improving the research design package before the performance of the full-scale research. Also, it avoids money and time wastage on an insufficiently designed project (Teijlingen, 2001). The fact that the study was carried out on a section of the sample size improves its relevance as well as reliability. Determination of population samples for the pilot study is determined by resource availability in terms of finances. "A rule of thumb" proposes a maximum population of $10 \%$ of the sample size (Teijlingen, 2001). Hence, $10 \%$ (9 respondents) of the sample size will be used for the pilot test.

\subsubsection{Validity of the Research Instruments}

The validity of an instrument is the degree in which an instrument performs its intended function. It is important in determining the efficiency of a system because it is nearly impossible to achieve an efficiency of $100 \%$. The validity of the questionnaire will be determined using construct validity. Construct validity is a measure of the degree to which data obtained from an instrument meaningfully and accurately reflects or represents a theoretical concept (Mugenda \& Mugenda, 2003).

\subsubsection{Reliability of the Research Instruments}

Reliability is defined as consistency of an instrument in its functions. It provides the degree of accuracy of an instrument. Cronbach's alpha $(\alpha)$ can be considered to be the anticipated correlation between a set of variables (Holborn, 2000) In order to improve the reliability of the tools, both the questionnaires and interview guides were standardized so that information collected could be sorted, entered and analyzed in a more consistent and accurate manner. The standardization also enhanced consistency in the questions being asked thereby eliminating bias and making information gathered more reliable.A formal reliability coefficient, Cronbach's Alpha Reliability Index was computed and reported for the scaled variables based upon the formula below:

$=\mathrm{RK} /[1+(\mathrm{K}-1) \mathrm{R}]$

Where " $\mathrm{k}^{\mathrm{M}}$ is the number of items considered and " $\mathrm{r}$ " is the mean of the inter-item correlations: the size of alpha was determined by both the number of items in the scale and the mean inter-item correlations. Gkofge and Mallery (2003) provide the following rules of thumb:

$>.9$ - Excellent, _> .8 - Good, _> .7 - Acceptable, _> .6 - Questionable, _> .5 - Poor and $<.5$ - Unacceptable" (p. 231). For this study, a score of 0.7 and above was considered having acceptable reliability in measuring the domain under investigation. Training of the research assistants (RAs) helped to enhance objectivity and overall quality of the data collection process.

\subsection{Data Analysis and Presentation}

Sorting, coding and entry of field data will be done by a data analyst under quality supervision and technical guidance of the- researcher. The Statistical Package for Social Science (SPSS) version 24 will be used to analysis data. The latest version incorporates the deployment and survey authority of numerical data using automated and batch scoring services (Field, 2005). The SPSS software is suitable for data analysis involving multiple regressions, Pearson correlations, and the Analysis of Variance (ANOVA). The resultant data presentation will be tabulated and presented using tables, bar graphs and pie charts.

Multiple regressions formula will be applied in this study to determine the relationship between the independent variables and one dependent variable. The formula for multiple regressions is expressed as follows: $Y=\beta_{0}+\beta_{1} X_{1}+\beta_{2} X_{2}+\beta_{3} X_{3}+\beta_{4} X_{4}+\varepsilon$, Where;

$\mathrm{Y}=$ Influence of SILC in informal finance groups in pastoral communities,

$\beta_{0}=$ constant (coefficient of intercept),

$\mathrm{X}_{1}=$; Financial Viability

$\mathrm{X} 2=$ Financial responsibilty

$\mathrm{X} 3=$ Information and Communication Technology; 
$\mathrm{X} 4=$ Financial sustainability;

$\boldsymbol{\varepsilon}=$ error term;

$\beta_{4}=$ regression coefficient of four variables.

An Analysis of Variance will be used to measure statistically the significance in predicting how dependent variables influence SILC for satisfaction. The test of significance is correlation coefficient, the $\mathrm{R}$ square as a measure of significance.

The coefficient is a standard measure of an assumed linear relationship between variables. A coefficient of value between (+ve) 0.5 and (-ve) 0.5 or higher indicates a strong relationship and by extension a significant variable in influencing the trend of the dependent variable.

\subsection{Correlations of all Variables}

Table 4. 1Model Correlations of all Variables

\begin{tabular}{|c|c|c|c|c|c|}
\hline & & Finan & Resp & ICT sustai & .In \\
\hline Financial viabi & yPearson Corre & & & - &.$^{*}$ \\
\hline & Sig. (2-tailed) & & . & & \\
\hline responsibility. & $\mathrm{N}$ & 98 & & & \\
\hline & Pearson Corre & $1-.112$ & 1 & . & - \\
\hline ICT & Sig. (2-tailed) & .266 & .002 & . & \\
\hline & $\mathrm{N}$ & 98 & 98 & 98 & \\
\hline & Pearson Corre & .453 & -.230 & -.1451 & \\
\hline Sustainability. & Sig. (2-tailed) & .231 & .149 & .367 & \\
\hline & $\mathrm{N}$ & 98 & 98 & $98 \quad 98$ & \\
\hline & Pearson Corre & $.382^{* *}$ & -.073 & $.226-.135$ & 1 \\
\hline Influence of SI & Sig. (2-tailed) & .000 & .650 & .156 .399 & \\
\hline & $\mathrm{N}$ & 98 & 98 & $98 \quad 98$ & 98 \\
\hline
\end{tabular}

**. Correlation is significant at the 0.01 level (2-tailed).

${ }^{\mathrm{xx}}$ Correlation is significant at the 0.05 level (2-tailed).

From the findings, a positive correlation is seen between each variable and performance. The strongest correlation was established between financial sustainability and Influence of SILC ( $\mathrm{r}=0.453$ and the weaker relationship found between Financial_viability and Influence of SILC ( $r=-0.112)$. financial responsibilty was found to be strongly and positively correlating with influence of SILC in informal groups correlation coefficient of 0.278 and 0.231 respectively. This is tandem with the findings of Camargo (2011), who observed that all the independent variables were found to have a statistically significant association with the dependent variable at over 0.05 level of confidence.

\subsection{Regression Analysis}

To establish the degree of influence of saving a and internal lending on pastoralists communities, a regression analysis was conducted, with the assumption that: variables are normally distributed to avoid distortion of associations and significance tests, which was achieved as outliers were not identified; a linear relationship between the independent variables and dependent variable for accuracy of estimation, which was achieved as the standardized coefficients were used in interpretation. The regression model was as follows:

$\mathrm{Y}=\alpha+\beta_{1} \mathrm{X}_{1}+\beta_{2} \mathrm{X}_{2}+\beta_{3} \mathrm{X} 3+\varepsilon$

saving $\mathrm{a}$ and internal lending on pastoralists communities $=\alpha+\beta_{1}$ (financial viability) $+\beta_{2}$ (financial responsibility) $+\beta_{3}$ (information and communication technology) $+\beta_{4}$ financial sustainability) + error term. Regression analysis produced the coefficient of determination and analysis of variance (ANOVA). Analysis of variance was done to show whether there is a significant mean difference between dependent and independent variables. The ANOVA was conducted at $95 \%$ confidence level.

\subsubsection{Model Goodness of Fit}

Regression analysis was used to establish the strengths of relationship between influence of SILC in informal finance groups in pastoral communities (dependent variable) and the predicting variables; financial viability, financial responsibility, information and communication technology and financial sustainability (independent variables). The results showed a correlation value $(\mathrm{R})$ of 0.858 which depicts that there is a good linear dependence between the independent and dependent variables.

Table 4.2 Model Goodness of Fit

\begin{tabular}{llll}
\hline $\mathbf{R}$ & $\mathbf{R}^{\mathbf{2}}$ & Adjusted $\mathbf{R}^{\mathbf{2}}$ & Std. Error of the Estimate \\
\hline 0.871 & 0.781 & 0.796 & 0.056 \\
\hline
\end{tabular}

a. Predictors: (Constants), financial viability, Financial responsibility, ICT, sustainability

b. Dependent Variable: influence of SILC in informal finance groups in pastoral communities 
With an adjusted R-squared of 0.781 , the model shows communication system, availability of net wort, training, $78.1 \%$ of the variations influence of SILC in informal finance groups in pastoral communities West Pokot County while $21.9 \%$ is explained by other indicators which are not inclusive in study or model. A measure of goodness of fit synopses the discrepancy between observed values and the values anticipated under the model in question (Capelli, 2010).

\subsection{Analysis of Variance (ANOVA)}

From the results in table 4.18 analysis of variance statistics was conducted to determine the differences in the means of the dependent and independent variables to show whether a relationship exists between the two. The Pvalue of 0.05 implies influence of SILC in informal finance groups in pastoral communities with financial viability, social cultural responsibility, information and communication technology, and environmental sustainability which is significant at $5 \%$ level of significance. This is in line with the findings of Barney (2011), who observed that this also depicted the significance of the regression analysis done at $95 \%$ confidence level. This implies that the regression model is significant and can thus be used to evaluate the association between the dependent and independent variables. This is in line with the findings of Berkowitz (2012) who observed that analysis of variance statistics examines the differences between group means and their associated procedures.

Table 4.3 ANOVA

\begin{tabular}{llllll} 
& Sum of Squares & Df & Mean Square & F & Sig. \\
\hline Regression & 4.147 & 1 & 1.049 & .514 & .004 \\
Residual & 6.433 & 95 & .495 & & \\
Total & $\mathbf{1 0 . 5 8 0}$ & $\mathbf{9 6}$ & & & \\
\hline
\end{tabular}

\subsection{Regression Coefficients of Determination}

To determine the relationship between the independent variables and the dependent variable and the respective strengths, the regression analysis produced coefficients of determination. Findings in table 4.18 above reveal a positive relationship between inventory management practices on service delivery and all the independent variables. Taking the regression model:

$Y=\alpha+\beta_{1} X_{1}+\beta_{2} X_{2}+\beta_{3} X_{3}+\beta_{4} X_{4}+\varepsilon ;$ where,

$\mathrm{Y}=$ motivation of employees for job satisfaction;

$\alpha=$ Constant; $\beta_{1}-\beta_{4}=$ Beta coefficients; $X 1=$ financial viability $X_{2}=$ financial responsibility; $X_{3}=$ information and communication technology; $\mathrm{X}_{4}=$ financial sustainability and $\varepsilon=$ Error term, from the result shown below, it's clear that when all the independent variables are regressed against the dependent variable the constant gives a negative result meaning there is a strong relationship and how each predictor has an influence on the dependent variable.

Table 4.4 Regression Coefficient Results

\begin{tabular}{llllll}
\hline & Unstandardized Coefficients & Standardized Coefficients & T & Sig. \\
& B & Std. Error & Beta & & \\
\hline (Constant) & -.183 & .060 & & -1.143 & .023 \\
Financial viability & .723 & .112 & .838 & 5.471 & .000 \\
Financial responsibilty & .149 & .068 & .162 & 2.471 & .041 \\
ICT & .344 & .059 & .587 & 4.386 & .000 \\
financial sustainability & .247 & .115 & .321 & 2.654 & .017 \\
\hline
\end{tabular}

Dependent Variable: influence of SILC in informal finance groups in pastoral communities

Constant: Reward, improve livelihood of the community, Continual upgrading of informal finance system, Improved lending services to the household, Promotes culture of savings

A unit change in inventory techniques would thus lead to a .723 influence of SILC in informal finance groups in pastoral communities ; while a unit change in training of would have an effect of .149 change in on inventory influences of SILC in informal finance groups in pastoral communities, also a unit change in ICT would have an influence of .344 change in on influence of SILC in informal finance groups in pastoral communities and finally a unit change in financial sustainability would have an effect of .247 change on influence of SILC in informal finance groups in pastoral communities. This implies that among other factors, inventory techniques, training, lead time and information technology are significant determinants of influence of SILC in informal finance groups in pastoral communities.

\subsection{Summary}

In summary, key findings under this area of study included the following: Although most respondents disagreed on the illusion that West Pokot had enough financial institutions, they concurred with the fact that West Pokot 
was profitable for financial institutions; Loan repayment system, consumer protection policy, impact on the poor and support to community owned financial providers had influenced on saving and internal lending communities in informal groups on pastoral communities. The influence of credit period designed by financial institutions on the selection of financial services could not be justified since majority of respondents were unsure (scored it at 2).

The third objective was to establish how financial acceptability influences on saving and internal lending communities in informal groups on pastoral communities in West Pokot County. Majority of the respondents agreed that the following financial concerns influenced selection of financial services in the Division: Ability to build mutually supportive finance; provision of social funds for community health care, cultural rites of passage, education and training; contribution to social status like improving livestock keeping and building/breaking of trust amongst members.

The findings revealed that $97 \%$ of the respondents agreed information and communication technology has a benefit on ensuring saving and lending is achieved. About the issue that the availability of network improves on saving and lending, the findings revealed that $100 \%$ of the respondents agreed with the statement. Majority of the respondents on the open-end question show that information and communication technology influences on saving and lending in that according to respondents they said ICT is important since it eases communication and all people can be reached hence having the information. According to the findings, the ability to provide a number of opportunities to improve financial sustainability of individual businesses had greatly influenced the choice of financial services in West Pokot. In addition, impact of a given financial service on the association level such as peer pressure, environmental education and training, symbolic and ethical environmental links as well as community coordinated implementation of the conservation and rural finance components had strong influence on its selection.

Influence of SILC in Informal Finance Groups in Pastoral Communities: The findings revealed that $100 \%$ of the all respondents agreed that saving and internal lending in pastoral communities in West Pokot if properly put in place it can; livelihood of the community, there should be continual upgrading of informal finance system, improved lending services to the household and the finance groups should promote the culture of savings. Majority of the respondents on the open-end question indicated that SILC in informal finance groups in pastoral communities was really influences how the community carries it activities.

\section{REFERENCES}

Adams D. \& Von Pischke J. (1992). Micro-enterprise credit programs',deja vu. World development, Ohio State University.

Adinyira, E., Oteng-Seifah, S., Adjei-Kumi,T. (2007). A review of urban sustainability assessment methodologies, Kumasi, Ghana

Anderson, S. \& Baland, J. (2002)." The economics of ROSCAs and intra household resource allocation.117 (3) 963-995. Oxford University Press

Ashley, C., \& Hussein, K., (2008). Developing methodologies for livelihood impact assessment: Experience of the African wildlife foundation in East Africa. Portland House London

Beijuka, J. \& Odele, S., (2007). SILC in Uganda, program review. Belshek, J. (n.d). Influence of Culture on the negotiation styles of British students, retrieved from http://research.ncl.ac.uk/ARECLS/voluine_3/jalalali.pdf on 3rd April 2012.

Brau J., Woller, G., (2004). Microfinance: a comprehensive review of the existing literature. Journal of Entrepreneurial Finance and Business Ventures 9(1): 1-26. Brigham University

Caletto, C., \& Morris, S., (1999) Designing methods for the monitoring and evaluation of the household food security rural development, projects. International food policy research institute.

Casley, D., and Lury, D., (1981). Data collection in developing countries. Oxford: Clarendon Press. Catholic Archdiocese of Mombasa (2010). SILC quarterly and monthly program progress reports. Mombasa Kenya.

Catholic Relief Services (CRS)., (2010). Savings and Internal Lending Communities Fiel Agent Guide Nairobi:

A. \& Dunn, E., (1996) Household Economic Portfolios, Washington DC: Management Systems International

Copestake J., Johnson, S., \& Wright, K. (2002) Impact assessment of micro-finance: Towards a New protocol for collection and analysis of qualitative data (Working paper no. 7). Brighton: Institute of development studies, University of Sussex 62'

Creevey, L., \& DAI, (2008). Common problems in impact assessment research Impact assessment primer series. Retrieved from http://pdf.usaid.gov/pdf_docs/PNADN201.pdf on 15th April 2012 DFID, (2000). Poverty elimination and the empowerment of women. Tropix, Minoli.

Donahue, J. (1999). A supplemental report on community mobilization and microfinance services as HIV/AIDS mitigation tools.U.S Agency for International Development

Elizabeth, L., Murdoch, J., \& Hashemi, S. (2003). Is microfinance an effective strategy to reach the millennium development goals? Retrieved from on 16th April 2012 from 
Fischer, C.S. (1992). America Calling: A Social History of the Telephone to 1940. Berkeley: University of California Press.

Ferguson, M (2012) SILC: Innovations, poverty outreach in fee for service saving group. CRS

Garbarino, S., \& Holland, J., (2009). Quantitative and qualitative methods in impact evaluation and measuring results. Retrieved from www.g3di1c.com

Gonzalez-Vega, C. (1977). Interest Rate Restrictions and Income Distribution. American Journal of Agricultural Economics.59 (5): 15-19.

Gwatkin, R., Rustein,S., Johnson,K., et al. (2000). Socio-Economic Differences in Health, Nutrition, and Population in Cameroon.

Habicht, J., Victora, G., \& Vaughan, J., (1997). Linking evaluation needs to design choices:A framework developed with reference to health and nutrition.

New York: Hendricks, L., (2000). Microfinance and culture. Case study in Ghana

Hulme, (n.d). Impact assessment methodologies for microfinance: Theory, experience and better Practice Institute for Development Policy and Management. University of Manchester

Hulme, D., Mosley, P., (eds) (1996). Finance against the poor (Volumes 1 and 2). London: Routledge.Journal of South Asian Studies, 24, (2), 353-369 July (2009).

The Socio-Economic and Demographic Determinants of Women Work Participation in Pakistan'. Evidence from Bahawalpur District.

Joppe, M. (2000). The Research Process. Retrieved February 25, 1998, Retrieved on 3ld April 2012 from http://www.ryerson.ca/ mjoppe/rp.htm 63

Kabeer, N., (2003). Assessing the 'wider' social impacts of microfinance services: Concepts, Methods, Findings. IDS Bulletin34(4): 106-114. Wiley online library

Kakwani, N., Wagstaff, A., \& Van Doorslaer, E., (1997). 'Socioeconomic inequalities in health: Measurement, computation, and statistical inference', Journal of Econometrics.77(1), 87-103. Elsevier

Karl an, D. (2001), Microfinance Impact Assessment: The perils of using new members as a Control group.M.I.T department of economics.

Karlan, D., (2008). The Impacts of Savings.M.I.T department of economics

Kirk, J., \& Miller, M. L. (1986). Reliability and validity in qualitative research. Beverly Hills: Sage Publications.

Kobb, D., (1997) "Measuring informal sector incomes in Tanzania. Some constraints to cost- benefit analysis", Small enterprise development, London

Kuate-Defo, B. (1997). 'Effects of socioeconomic disadvantage and women's status on women's health in Cameroon', Social Science and Medicine 44(7), 1023-1042. Cameroon.

Kuate-Defo, B., \& Diallo, K., (2002). 'Geography of child mortality clustering within African families', Health and Place8(2), 93-117. Cameroon

Landman, R. \& Tinnermeler, R., (1981) "The political economy of agricultural credit: The case of Bolivia,"American Journal of Agricultural Economics, 63, (1), 66-72

Makina, D., Malobola, L., (2004). Impact assessment of microfinance programmes, including lessons from Khula Enterprise Finance. Development Southern Africa21(5) 799-814

Mayoux, L., (1999). Questioning virtuous spirals: Microfinance and women's empowerment in Africa. Journal of International Development11: 957-984. Geneva

Mayoux, L., (2013), Impact assessment of microfinance: Towards a sustainable lending process Open university, Milton, Keynes

Montgomery, R (1996) 'Disciplining or protecting the poor? Avoiding the social costs of peer Pressure in micro-credit schemes Journal of International Development (2), 289-305

Mugenda O. M \& Mugenda O. G. (1999), Research Methods: Quantitative and Qualitative Approaches, Nairobi.

Oakes, M., \&'Rossi,P., (2tT03). 'The measurement of SES in health research: Current practice and steps toward a new approach', Social Science and Medicine. Sage publications64 